\title{
Investigating the Effect of Selected Marketing Efforts in Brand Equity Creation and Its Cross-Cultural Invariance in Emerging Markets
}

\author{
Isaac Twum Asare ${ }^{1} \&$ Shen Lei ${ }^{1}$ \\ ${ }^{1}$ Glorious Sun School of Business and Management, Donghua University, Shanghai, China \\ Correspondence: Shen Lei, Glorious Sun School of Business and Management, Donghua University, Shanghai, \\ China. E-mail: slei@dhu.cn
}

Received: December 5, 2016 Accepted: December 23, $2016 \quad$ Online Published: January 16, 2017

doi:10.5539/ijms.v9n1p91 URL: http://dx.doi.org/10.5539/ijms.v9n1p91

\begin{abstract}
In the field of brand management, numerous studies have been conducted on brand equity conceptualization, measurement and validation. Also, previous researchers have shown that consumer-based brand equity via its dimensions can be created and maintained through a company's marketing mix activities. Brand equity according to Keller, is the differential effect of brand knowledge on consumer response to the marketing activities performed on the brand. Due to cultural differences, consumers' reaction will differ and thus these marketing efforts will have varying results in different markets.

Drawn from both Aaker's \& Keller's conceptualizations of brand equity, the current study develops a brand equity creation process model similar to Yoo et al.'s and examines its cross-cultural invariance through a structural invariance test using data from two important growing markets - Ghana and China. Results prove that some marketing efforts and dimensions of brand equity have invariant effects on brand equity across the Ghana and Chinese samples. Specifically, the effect of price on perceived quality was not equivalent in both markets. Relationship among brand equity dimensions were also not equivalent, however these dimensions all show an equivalent, positive effect on brand equity. Managerial implications for international brands and limitations for future research are discussed.
\end{abstract}

Keywords: brand equity, cross-cultural invariance, marketing mix elements, structural invariance test, structural equation model (SEM), Hofstede's dimensions

\section{Introduction}

With the increased competition in today's business environment, creating differentiation is a significant competitive marketing strategy to be successful. Successful brands are creating such differentiation by building strong brands. Branding remains the industry's largest source of competitive advantage. Brand equity creates value to the firm by enhancing efficiency and effectiveness of marketing programs, brand loyalty, price premiums, brand extensions, trade leverage, etc.; and value to the customer via enhanced information interpretation and processing purchase decision confidence and satisfaction.

Yoo et al. (2000) using a structural model composed of three components: marketing mix elements (i.e., price, store image, distribution intensity, advertising spending and price deals), brand equity dimensions (i.e., perceived quality, brand loyalty and brand awareness/associations), and overall brand equity investigated the relationships between selected marketing mix elements and the creation of brand equity among US consumers. Two years later, Yoo \& Donthu selected Korea, a country with a culture distinctively different from the US and explored the generalizability of this brand equity formation process and verified the model's factorial invariance. Findings from their study suggest that cultural contexts significantly moderate marketing activities and brand equity formation (Yoo \& Donthu, 2002), thus the influence of culture on consumer buying behavior cannot be disregarded by international brand managers.

With the increase trend of internationalization, global marketing has become more and more important over the years. Most major brands are competing on international level and faced with the challenge of which international market to enter and the appropriate marketing strategies to apply in these respective countries. It is of utmost important for brand managers to build strong brands in international markets, and understanding of the brand equity creation process in the target market is necessary (Yoo \& Donthu, 2002). Two important growing 
markets with huge opportunities in today's business world are China and Africa. These two markets remains top priority for most major brands.

In Africa, Ghana has established itself as an important gateway to the West African market and is considered among the world's fastest growing countries. Key supporting factors are its abundant natural resources, economic liberalism, diverse economy and track record of political stability. In recent years, there has been an increase influx of foreign brands into the country competing with local brands to gain a share of this growing market. In Asia, China is undoubtedly a large and important market to many international brands. The China market of 1.3 billion people - coupled with the meteoric rise of both the size and spending power of its middle class continues to deliver important revenue to many brands. The Chinese consumer is a driving force to global growth. It is thus important to validate the brand equity formation process proposed by (Yoo et al., 2000) in these two markets to help brand managers devise effective marketing mix elements to build strong brands, thus gain competitive advantage.

The main purpose of the current study is to explore the generalizability of Yoo et al. (2000) brand equity creation model in other cultures different from the US and Korea by examining the relationship between the selected marketing efforts and brand equity dimensions. United States is a country characterize with low power distance and uncertainty avoidance, it is also a masculine society and very individualistic. On the other hand, Korea is a society with strong uncertainty avoidance, collectivistic, feminine and high power distance. These cultural dimensions especially individualism and uncertainty avoidance did significantly affect the brand equity formation process across the two markets. Culture in Ghana is more similar to Korea and thus expected to have similar results of Yoo \& Donthu (2002).

Table 1. Summary of culture dimensions for each country

\begin{tabular}{lllll}
\hline & USA & Korea & Ghana & China \\
\hline Power Distance & Low & High & High & High \\
Collectivism & Low & High & High & High \\
Uncertainty Avoidance & Low & High & High & Low \\
Masculinity & High & Low & Low & High \\
\hline
\end{tabular}

In this present study, Yoo et al. (2000) model for brand equity creation is revised to consist of three selected marketing efforts (i.e., price, advertising spending and price promotion), three brand equity dimensions (i.e., perceived quality, brand image and brand loyalty), and overall brand equity. The relationship between the selected marketing efforts and brand equity dimensions will be first analyzed, followed by investigating the relationship between the brand equity dimensions. Theses analyses will be performed on each sample - Ghana and China (Individual analysis). Finally, the structural model invariance will be tested using the total sample.

To accomplish the aim of the study, this paper begins with a review of literature on consumers-based brand equity, followed by examining the antecedents and dimensions of brand equity, and a description of the hypotheses of the study. Next, the methodology and measurement scales used are outline, and the empirical results presented. Finally, the major conclusions, managerial implications, limitations and recommendation for future research are commented on.

\section{Literature Review}

\subsection{Marketing Mix Elements and Brand Equity}

Many authors agree that brand equity can be created, maintained and expanded by strengthening the dimensions of brand equity. Researchers have catalogued the apparent effects of various marketing efforts and market conditions on brand equity. Using marketing activities very effectively can increase brand equity, however, some can also decrease brand equity. In their model results, Yoo et al. (2000) revealed two types of marketing managerial efforts; brand building and brand harming. Frequent use of price promotions is an example of brand harming activity, whereas high advertising spending, high price, distribution through retailers with positive store image and high distribution intensity are examples of brand building activities. Simon \& Sullivan (1993) listed advertising expenditures, sales force and marketing research expenditures, age of the brand, advertising share, order of entry, and product portfolio as sources of brand equity. Other marketing activities, such as the use of public relations Aaker (1991), warranties (Boulding \& Kirmani, 1993), slogans or jingles, symbols, and packages (Aaker, 1991), have also been proposed. According to Keller (2002), several marketing communications (e.g., advertising, promotion, event marketing/sponsorship, and public relations) have positive 
effects on brand equity. He further suggests that different marketing activities have different contributions. Advertising, for example, is often the central element of a marketing communications program to create brand equity because it initiates the creation of brand equity by building brand image (brand awareness and association).

For this study, price, advertising spending and price deals are selected as the marketing activities or antecedents of brand equity. These selected marketing activities represent the most commonly and similar strategies employed by the selected brands in both markets (Ghana and China) in the process of building brand equity. What impact does high price have on brand equity? What is the role of advertising spending in sustaining and building brand equity? Do sales promotions in a given market have a positive or detrimental effect on brand equity? In the next section, each selected marketing effort is reviewed and their hypothesized relationships with the brand equity dimensions are presented.

\subsubsection{Advertising Spending}

A lot of research has been investigated on how actual and perceived advertising spend influences brand equity through its dimensions (Bravo et al., 2007; Cobb-Walgren et al., 1995; Simon \& Sullivan, 1993; Villarejo-Ramos \& Sánchez-Franco, 2005; Yoo et al., 2000). Perceived advertising spend can influence brand equity through its dimensions and is one extrinsic quality cue consumers use in judging products quality (Kirmani \& Rao, 2000). In this study, the consumers perceived advertising spending of the brand will be measured. Heavy advertising spending reflects the firm's investments in the brand, implying superior quality (Yoo et al., 2000). Advertising has a central role to play in developing brand image. It's an effective way to communicate and convey message (provide product information) to consumers to create credibility, reduce ambiguity. Advertising is a great tool that aid to communicate a brand's expertise and willingness to deliver what is promised.

In summary, advertising increase the familiarity of a brand to consumers and it shapes their perceptions towards the brand. Lindsay (1990) argues that the greatest source of added value is consumer perceptions of the brand which is derived from advertising that build brand image. Furthermore, Rice \& Bennett (1998) found out that effective advertising not only increase the awareness of the brand but also improve attitudes toward the brand and strengthen its image. According to the framework of the causal order, advertising reinforces brand related associations and attitude towards the brand (Yoo et al., 2000) making it also positively related to brand loyalty.

H1a: The higher the advertising spending of the brand, the higher the brand's image

H1b: The higher the advertising spending of the brand, the higher the brand loyalty

H1c: The higher the advertising spending of the brand, the higher the perceived quality

\subsubsection{Price Promotion}

Price promotions argued by many researchers are often used to gain short-term volume that has little positive impact in the long-term. In a short term, price promotion can increase market share, encourage brand switching and induce product trial usage (Blattberg \& Neslin, 1990; Leone \& Srinivasan, 1996). Frequent price promotions in a long term have been linked to eroding a brand's perceived quality since they reduce the product price (Bravo et al., 2007) resulting in a decrease of brand health and equity. Frequent use of price promotions generates uncertainty about the brand quality, resulting in an increase negative brand perception. It also generates a brand image perception of poor quality. These activities provoke consumers' confusion; instability and variability (Villarejo-Ramos \& Sánchez-Franco, 2005) leading to an image of unstable quality.

Findings from many research works on the relation between price promotion and perceive quality shows a negative relation and this study also seeks to investigate this relationship.

H2a: The use of price promotions has a negative effect on its brand image

H2b: The use of price promotions has a negative effect on its perceived quality

\subsubsection{Price}

Price is seen as something different and distinct from other antecedents of brand equity, a variable that customers weigh against their feelings about a brand. Keller (2002) argues consumers often infer the quality of a product based on the price it is sold. The status of many luxury brands are underpinned by the price they are sold. Its high price sets it apart and makes it exclusive. Many authors (Bravo et al., 2007; Yoo et al., 2000) have examined the relation between price and brand equity and have all concluded that there is a positive relation between price and brand equity. High price brands are often perceived to be of higher quality. Therefore price is positively related to brand equity through is perceived quality dimension. 
H3a: The higher the price, the higher the perceived quality

\subsection{Consumer-Based Brand Equity (CBBE)}

Both academicians and practitioners have strong interest in brand equity (Cobb-Walgren et al., 1995). Consumer-based brand equity is analyzed from the consumer response to a brand name (Bravo et al., 2007; Keller, 2003). Aaker $(1991,1996)$ proposes that brand equity is a multidimensional concept consisting mainly of brand loyalty, brand awareness, perceived quality and brand associations. Keller (1993) however suggests customer-based brand equity is comprised of two parts: customer perceptions (brand knowledge) and behaviors (brand responses), and defines brand knowledge in terms of brand awareness and brand image. Lassar et al. (1995) defines brand equity as "the enhancement in the perceived utility and desirability a brand name confers in a product" and suggest brand equity is based on five underlying dimensions: performance, value, social image, trustworthiness and commitment, whereas Srivastava \& Shocker (1991) view brand equity as consisting two components-brand strength and brand value.

In this study, the author proposes three constructs that is drawn from both Aaker \& Keller conceptualization of brand equity. These are brand image, perceived quality and brand loyalty.

\subsubsection{Brand Image}

Brand image has long been recognized as an important concept in marketing Keller (1993) defines brand image as "perceptions about a brand as reflected by the brand associations held in consumer memory". Similarly, brand image is also defined by Low \& Lamb (2000) as the reasoned or emotional perceptions consumers attach to specific brands. Consistent with previous authors' definition, Cretu \& Brodie (2007) define it as the consumers' mental picture of the offering which includes symbolic meanings that consumers associate with specific attributes of the product or service. Therefore, brand association is considered an important factor in several brand image studies. These associations formed in the minds of consumers contain the meaning of the brand to them. Brand association is often based on the associative network model (Farquhar et al., 1992) in which a person's memory consists of a network of nodes (stored information or concepts) and connecting link (strengths of associations between the information or concept). Before consumers hold any form of associations in minds about brands, they first need to be aware of these brands. Brand awareness is a prevalent selecting factor among customers (Cobb-Walgren et al., 1995) and relates to the likelihood that a brand name easily comes to the mind of a consumer. There exist an inter-relationship or high correlation between brand awareness and brand association (Atilgan et al., 2005; Pitta \& Prevel, 1995; Washburn \& Plank, 2002; Yoo \& Donthu, 2001; Yoo et al., 2000) due to both dimensions arising from consumer-brand contact (Aaker, 1991). These two dimensions precede perceived quality and brand loyalty in the hierarchy of effects model (Lavidge \& Steiner, 2000; Yoo et al., 2000).

A positive brand image can be use to differentiate itself among competitors thereby enhancing customer loyalty, and increasing profits (Wu et al., 2011). Both brand association and awareness are related to the brand's links and nodes in memory. It can thus be proposed that the image a consumer will have about a brand is based on (1) the level of awareness of the brand and (2) the type of associations formed with the brand. In this current study brand image is defined to be a joint dimensional construct that consist of brand awareness and brand association.

\subsubsection{Perceived Quality}

There has been an increased recognition by practitioners of the importance of perceived quality across all product and service categories (Tong \& Hawley, 2009). This is based on consumer's subjective evaluations of a product's quality. Zeithaml (1988) defines perceived quality as the "consumer's judgments about a products overall excellence or superiority". A consumer's personal experience with a product, unique needs and expectations, consumption condition may influence the consumer's judgments of the product quality (Yoo \& Donthu, 2001). A products performance, features, reliability, durability, serviceability are some factors that influence its perceived quality. Perceived quality is regarded as a core Customer-Based Brand Equity construct because of its association with the willingness to pay a price premium, intention to purchase a brand and choice of brand (Netemeyer et al., 2004).

\subsubsection{Brand Loyalty}

Creating, building and maintaining brand loyalty has been an important issue for most marketers in establishing sustainable competitive advantage. Aaker (1991) argues the importance of brand loyalty in evaluating a brand in terms of value because this dimension of brand equity can generate profit. Brand loyalty, a reflection of brand equity refers to the tendency to be committed to a focal brand demonstrated through the intention of purchasing that brand as a primary choice (Oliver, 1999). Routine purchase of a brand without switching to other brand is 
referred to as brand loyalty. This brand equity dimension is composed of two different components; attitudinal (which includes cognitive, affective and behavioral intent dimensions) and behavioral (repeat buying behavior) (Dick \& Basu, 1994; Taylor et al., 2004). This dimension plays an outstanding role in creating brand equity (D. Aaker, 1991; Grover \& Srinivasan, 1992) and is qualitatively different from the other dimensions in that it is linked to prior purchases and experiences.

\subsection{Relationship among Dimensions of Brand Equity}

The dimensions of brand equity are very closely interrelated and previous studies have determined directional relationship exist among the brand equity dimensions. Brand awareness is considered by many studies as the first causal-order stage, followed by brand association then perceived quality. This causal order argued by Chiong et al. (2013) was based on the cognitive - affective - behavioral hierarchical model. Brand loyalty is the last dimension which occurs after repeat purchase.

Roberts et al. (2004) used the purchase decision stages to justify this causal order of the dimensions of brand equity. This possible causal order between these dimensions was also argued by Yoo et al. (2000) and based their arguments on the hierarchy of effects theory. Thus proposing that marketing activities may have an impact on customers associations with the brand as well as how the quality of the brand is perceived, and this may then result in brand loyalty.

Buil et al. (2013) used the traditional hierarchy of effects model to propose their hypotheses about the relationship among brand equity dimensions. The theory posits that attitudes and subjective norms influence intentions, which in turn affect behavior. According to this model, consumers are very highly involved in making their purchasing decisions, which means they are motivated to seek out information about the product thereby forming beliefs, then evaluate alternatives and finally make the decision whether to purchase or not. This causal order framework reveals the stages of brand equity creation as a consumer learning process (Buil et al., 2013). Consumers' awareness of a brand leads to brands association and perceived quality, which will in turn influence brand loyalty.

For this research, the causal-order process is proposed to follow this path: Brand Image $\Rightarrow$ Perceived Quality $\Rightarrow$ Brand Loyalty $\Rightarrow$ Overall Brand Equity. Perceived quality is partly based on the level of awareness and association strength a consumer has about a brand. Brands perceived to be of high quality are recognized as very distinct and superior. As a result, consumers purchase such brands which results in behavioral and attitudinal loyalty in a long term. Moreover, other relationships are also examined. Previous studies agree that these brand equity dimensions have significant inter-correlations among them.

Based on these arguments, the following relationship hypotheses are proposed among these dimensions:

H4a: The higher the brand image, the higher the perceived quality

H4b: The higher the brand image, the higher the brand loyalty

H4c: The higher the brand image, the higher the overall brand equity

H5a: The higher the perceived quality, the higher the brand loyalty

H5b: The higher the perceived quality, the higher the overall brand equity

H6a: The higher the brand loyalty, the higher the overall brand equity 


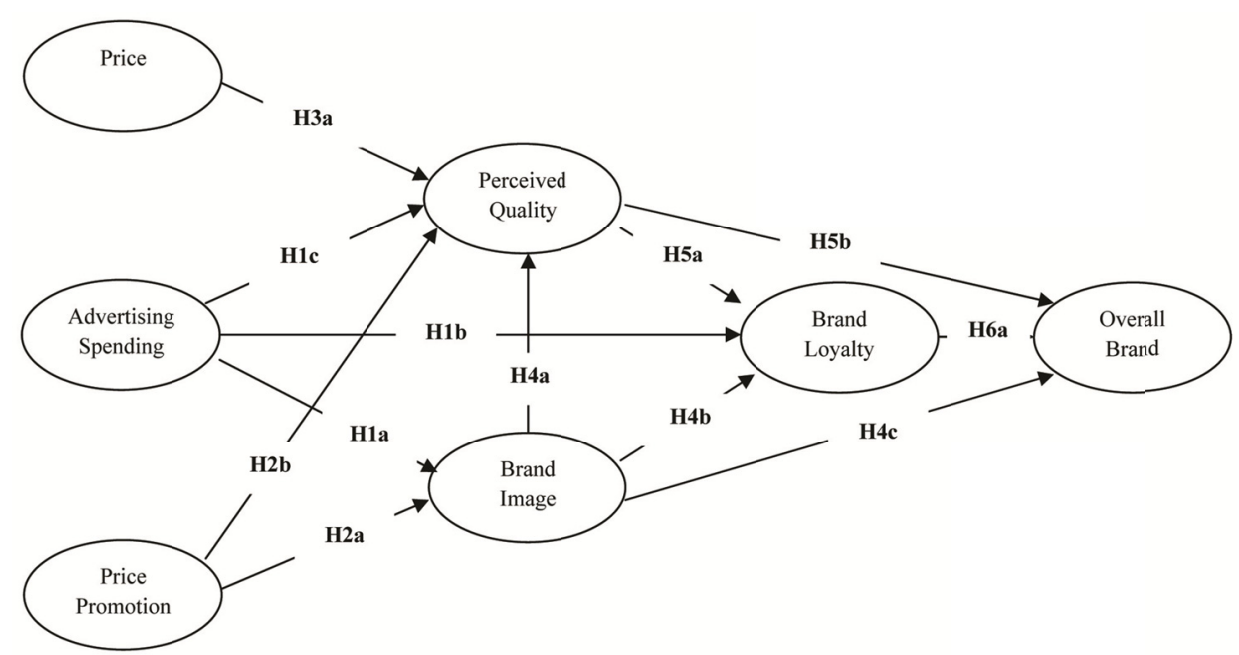

Figure 1. Relationship between marketing activities and brand equity dimensions

\section{Methodology}

A stratified random sampling method was employed to gather data for the empirical work which were obtained through a self-administered online surey in both Accra (Ghana) and Shanghai (China). Undergraduate students and consumers in the work force were the main respondents employed in the study.

In selecting which product categories to use in this study, the degree of familiarity and its consumption or usage level by both consumers in Ghana and China were considered. These ensured respondents provide reliable and valid responses to the questionnaires. Other factors considered when selecting the brands for the product categories was price, purchase frequency, quality, market share, marketing strategies, country of origin and consumption situation (Yoo et al., 2000).

As a result, athletic shoes and jeans were selected. Another important reason is the large value percentage of this product categories attribution to brand equity variance, which is a condition favorable for brand equity studies (Simon \& Sullivan, 1993; Yoo \& Donthu, 2001). Eight brands were selected, four for each product category: Adidas, Nike, Puma and Reebok for athletic shoes and Levis, Wrangler, Diesel and Armani for the jeans category. The high number of brands included in the study was to ensure respondents could at least find one among them with which they were familiar and thus increase response reliability. All the selected brands are comparatively known by consumers in both Ghana and China. Among the eight brands, respondents can provide response to only one brand.

A four-part questionnaire was used to measure the variables or constructs in the study to test the formulated research hypotheses. The likert scale, a psychometric scale developed by Rensis Likert was employed to measure these constructs. The items scales for measuring the marketing activities and brand equity and its dimensions were evaluated with five point Likert scales anchored at 1= "Strongly Disagree" and 5= "Strongly Agree". The items or measures used in the study were borrowed from previous measures. These scales are shown in Table 2.

Table 2. Constructs of the questionnaire

\begin{tabular}{|c|c|c|c|c|}
\hline Part & Construct & & Developers & Items \\
\hline \multirow{3}{*}{1} & \multirow{3}{*}{ Marketing Mix Elements } & Price & & 3 \\
\hline & & Advertising Spending & Yoo et al. (2002) & 3 \\
\hline & & Price Promotion & & 3 \\
\hline \multirow{6}{*}{2} & \multirow{6}{*}{$\begin{array}{l}\text { Dimensions of Consumer-Based } \\
\text { Brand Equity }\end{array}$} & \multirow{2}{*}{ Perceived Quality } & Yoo et al. (2002) & 5 \\
\hline & & & Pappu et al. $(2005,2006)$ & 1 \\
\hline & & Brand Image & Villarejo \& Sanchez (2005) Lasser et al. (1995) & 7 \\
\hline & & \multirow{2}{*}{ Brand Loyalty } & Yoo et al. (2000) & 3 \\
\hline & & & Gil et al. (2007) & 1 \\
\hline & & Overall Brand Equity & Yoo et al. $(2000)$ & 4 \\
\hline 3 & Demographics & & Author & \\
\hline
\end{tabular}


A total of 636 responses (250 from Ghana and 386 from China) were received from the online survey. After invalid responses were excluded, a usable sample of 416 responses was obtained. Among the 416 responses, 114 completed for the jeans category and 302 completed for the athletic shoes category.

In the Ghana sample, the respondents were made up of 101 men (49.8\%) and 102 women (50.2\%). Approximately around $75 \%$ were aged between 18 and 35 years. The Ghana sample attained a response rate of $81.2 \%$ and majority selected the athletic shoe category as the product category they are more familiar with and both Nike and Adidas are the top brands with high awareness level. In the China sample, 54\% were women and about $70 \%$ were aged between 18 and 35 years old. Response rate in the China sample was low (51.2\%) compared to the Ghana sample. Their most familiar athletic shoe brand and jeans brand are Nike $(48.7 \%)$ and Levis (45.6\%) respectively.

\section{Data Analyses}

Reliability analysis, exploratory analysis and confirmatory analysis were performed to explore whether common items and similar pattern of internal consistency and dimensionality among brand equity items could be found in each of the two samples.

Reliability analysis was conducted separately for the items of each construct to determine the discriminative power and internal consistency of the measurement scale using item-to-total correlation and cronbach's alpha. Cronbach alpha $(\alpha)$ coefficient is the most general measure of reliability for a multi-item scale (Sekaran, 1992). Previous studies suggests a cut-off point of 0.7 more suitable (Churchill, 1979; Nunnally, 1978; Spector, 1992) as this is the minimum value to be employed for assessing the internal consistency of the construct. As a result, 4 items were deleted and 26 were retained for the 7 constructs.

EFA was the next data analysis conducted to check the unidimensionality of the measures used and also whether the individual items are loaded on their appropriate factors as intended (Hair et al., 2005). Maximum Likelihood using orthogonal rotation, specifically varimax rotation was employed. All factor loadings were above 0.5 (Doll \& Torkzadeh, 1988) in both groups and seven distinct constructs emerged in both samples.

Results of both EFA and reliability analyses confirm the unidimensionality of each construct in the model for each sample and also the internal consistency of each construct. All the items loaded on the appropriate factors and no item loaded on more than one factor, supporting the independence of the constructs and providing strong empirical evidence of their validity. Table 3 provides the factor loadings of the items for both groups. All measures appeared to be good indicators of each construct.

Table 3. Results of exploratory factor analysis for both samples

\begin{tabular}{|c|c|c|c|c|}
\hline \multirow[t]{2}{*}{ Constructs/Items } & \multicolumn{2}{|l|}{ Ghana Sample } & \multicolumn{2}{|l|}{ China Sample } \\
\hline & Factor Loadings & $\%$ of Variance & Factor Loadings & $\%$ of Variance \\
\hline Advertising Spending & & 6.323 & & 6.755 \\
\hline ADS1 & .605 & & .852 & \\
\hline ADS2 & .616 & & .556 & \\
\hline ADS3 & .809 & & .753 & \\
\hline Price & & 6.471 & & 6.235 \\
\hline $\mathrm{P} 1$ & .504 & & .591 & \\
\hline $\mathrm{P} 2$ & .463 & & .531 & \\
\hline P3 & .967 & & .854 & \\
\hline Price Promotion & & 8.341 & & 9.764 \\
\hline PP1 & .852 & & .893 & \\
\hline PP2 & .767 & & .897 & \\
\hline PP3 & .858 & & .893 & \\
\hline Perceived Quality & & 10.013 & & 10.625 \\
\hline PQ1 & .685 & & .614 & \\
\hline PQ2 & .698 & & .737 & \\
\hline PQ3 & .535 & & .630 & \\
\hline PQ4 & .660 & & .599 & \\
\hline PQ5 & .749 & & .762 & \\
\hline Brand Loyalty & & 6.741 & & 7.654 \\
\hline BL1 & .726 & & .802 & \\
\hline BL2 & .608 & & .779 & \\
\hline BL3 & .736 & & .689 & \\
\hline
\end{tabular}




\begin{tabular}{|c|c|c|c|c|}
\hline Brand Image & & 12.357 & & 9.631 \\
\hline BM1 & .773 & & .788 & \\
\hline BM2 & .720 & & .577 & \\
\hline BM3 & .775 & & .522 & \\
\hline BM4 & .724 & & .534 & \\
\hline BM5 & .720 & & .843 & \\
\hline Overall Brand Equity & & 10.156 & & 9.169 \\
\hline OBE1 & .766 & & .767 & \\
\hline OBE2 & .734 & & .697 & \\
\hline OBE3 & .735 & & .691 & \\
\hline OBE4 & .677 & & .694 & \\
\hline
\end{tabular}

Finally confirmatory factor analysis (CFA) was employed to test the measurement structure and examine how well the data set fits the hypothesized measurement structure (Dabholkar et al., 1995). CFA was undertaken using IBM SPSS AMOS 21 and this analysis enables a comprehensive assessment of convergent validity and discriminant validity (Anderson \& Gerbing, 1984; Campbell \& Fiske, 1959). The Maximum Likelihood (ML) method was applied to the CFA model.

The overall fit statistics of both measurement models are presented in Table 4 . The chi-square $\left(\chi^{2}\right)$ values were statistically significant at the 0.05 level. The fit indexes indicate a good level of fit of both models (Hu \& Bentler, 1999). The clean factor loadings found in the exploratory factor analyses were consistently found in the confirmatory factor analyses.

Table 4. Overall fit statistics of measurement model

\begin{tabular}{llll}
\hline Goodness-of-fit Statistics & Desired values for Good Fit & Ghana Model & China Model \\
\hline Chi-square/df & $<3$ good & $453.410 / 278$ & $385.072 / 278$ \\
p-value for the model & $>0.05$ & 0.000 & 0.000 \\
CFI & $>.95$ great & 0.927 & 0.958 \\
GFI & $>.95$ & 0.865 & 0.881 \\
AGFI & $>.80$ & 0.83 & 0.85 \\
RMR & $<.09$ & 0.04 & 0.031 \\
IFI & $>.90$ & 0.929 & 0.959 \\
NFI & $>.90$ & 0.835 & 0.867 \\
RMSEA & $<.05$ good; .05-.10 moderate & 0.056 & 0.043 \\
\hline
\end{tabular}

Composite reliability statistics for all constructs were above 0.7 , ranging from 0.751 to 0.944 in the Ghana sample and 0.754 to 0.942 in the Chinese sample. In this study, with the exception of the brand image construct in the Chinese sample, the average of variances extracted (AVE) for all other constructs in each group were all over 0.50 , thus confirming the convergent validity of all the latent constructs (See Table 5). This low AVE resulted from the low correlation between items. Table 6 reports the correlation among the brand image items for Ghana and China.

Table 5. Constructs validity results for Ghana and China sample

\begin{tabular}{lclll}
\hline & Ghana Sample & \multicolumn{3}{l}{ Chinese Sample } \\
\hline & CR & AVE & CR & AVE \\
\hline Advertising Spending & 0.766 & 0.524 & 0.799 & 0.575 \\
Price & 0.751 & 0.505 & 0.754 & 0.511 \\
Price Promotion & 0.876 & 0.703 & 0.942 & 0.843 \\
Perceived Quality & 0.766 & 0.524 & 0.842 & 0.519 \\
Brand Loyalty & 0.782 & 0.546 & 0.838 & 0.633 \\
Brand Image & 0.893 & 0.626 & 0.814 & 0.474 \\
Overall Brand Equity & 0.863 & 0.612 & 0.855 & 0.597 \\
\hline
\end{tabular}

Note. Composite Reliability (CR), Average Variance Extracted (AVE). 
Table 6. Correlation for brand image items for Ghana and Chinese data

\begin{tabular}{llllll}
\hline & BM1 & BM2 & BM3 & BM4 & BM5 \\
\hline BM1 & 1 & .441 & .446 & .385 & .718 \\
BM2 & .559 & 1 & .441 & .426 & .492 \\
BM3 & .675 & .627 & 1 & .511 & .417 \\
BM4 & .613 & .648 & .644 & 1 & .442 \\
BM5 & .610 & .664 & .644 & .581 & 1 \\
\hline
\end{tabular}

Notes. The left off-diagonal matrix represents the Ghana data $(\mathrm{n}=203)$ and the right off-diagonal matrix represents the Chinese data $(\mathrm{n}=213)$. Correlation is significant at the 0.01 level (2-tailed), $\mathrm{BM}=$ Brand Image.

To achieve discriminant validity, the average of variance extracted estimates in each construct should exceed the squared inter-construct correlations associated with constructs in the model (Hair et al., 2005). All the average variance extracted estimates are all greater than the corresponding inter-construct squared correlation estimates, showing discriminant validity. See Table 7 and 8 for results for Ghana and China respectively.

CFA results revealed that none of the indicators were problematic and the measures in the study for both samples are adequate and the scales exhibit high convergent and discriminant validity.

Table 7. Factor correlation matrix with square root of the AVE on the diagonal (Ghana sample)

\begin{tabular}{llllllll}
\hline & ADS & P & PP & PQ & BL & BM & OBE \\
\hline ADS & 0.724 & & & & & & \\
P & 0.333 & 0.71 & & & & & \\
PP & -0.082 & -0.177 & 0.839 & & & & \\
PQ & 0.408 & 0.347 & -0.234 & 0.712 & & & \\
BL & 0.267 & 0.418 & -0.059 & 0.301 & 0.739 & & \\
BM & 0.421 & 0.466 & -0.276 & 0.312 & 0.39 & 0.791 & \\
OBE & 0.32 & 0.284 & -0.042 & 0.542 & 0.47 & 0.422 & 0.782 \\
\hline
\end{tabular}

Note. Advertising Spending (ADS), Price (P), Price Promotion (PP), Perceived Quality (PQ), Brand Loyalty (BL), Brand Image (BM), Overall Brand Equity (OBE).

Table 8. Factor correlation matrix with square root of the AVE on the diagonal (China sample)

\begin{tabular}{llllllll}
\hline & ADS & P & PP & PQ & BL & BM & OBE \\
\hline ADS & 0.758 & & & & & & \\
P & 0.198 & 0.715 & & & & & \\
PP & -0.204 & -0.184 & 0.918 & & & & \\
PQ & 0.274 & 0.524 & -0.285 & 0.72 & & & \\
BL & 0.15 & 0.162 & -0.059 & 0.417 & 0.796 & & \\
BM & 0.317 & 0.317 & -0.293 & 0.175 & 0.073 & 0.688 & \\
OBE & 0.31 & 0.369 & -0.128 & 0.479 & 0.477 & 0.326 & 0.773 \\
\hline
\end{tabular}

Note. Advertising Spending (ADS), Price (P), Price Promotion (PP), Perceived Quality (PQ), Brand Loyalty (BL), Brand Image (BM), Overall Brand Equity (OBE).

\subsection{Structural Model Testing_Individual Analysis / Subgroup Analysis: Ghana and China Samples}

After evaluating the measurement model in terms of reliability, convergent and discriminant validity for both samples, Structural Equation Modeling (SEM) was used to examine the relations among the latent variables. IBM SPSS AMOS 21 was employed to run the structural model and estimate the parameters by testing the hypothesized relationships between the constructs using the Maximum Likelihood (ML) estimation method. 


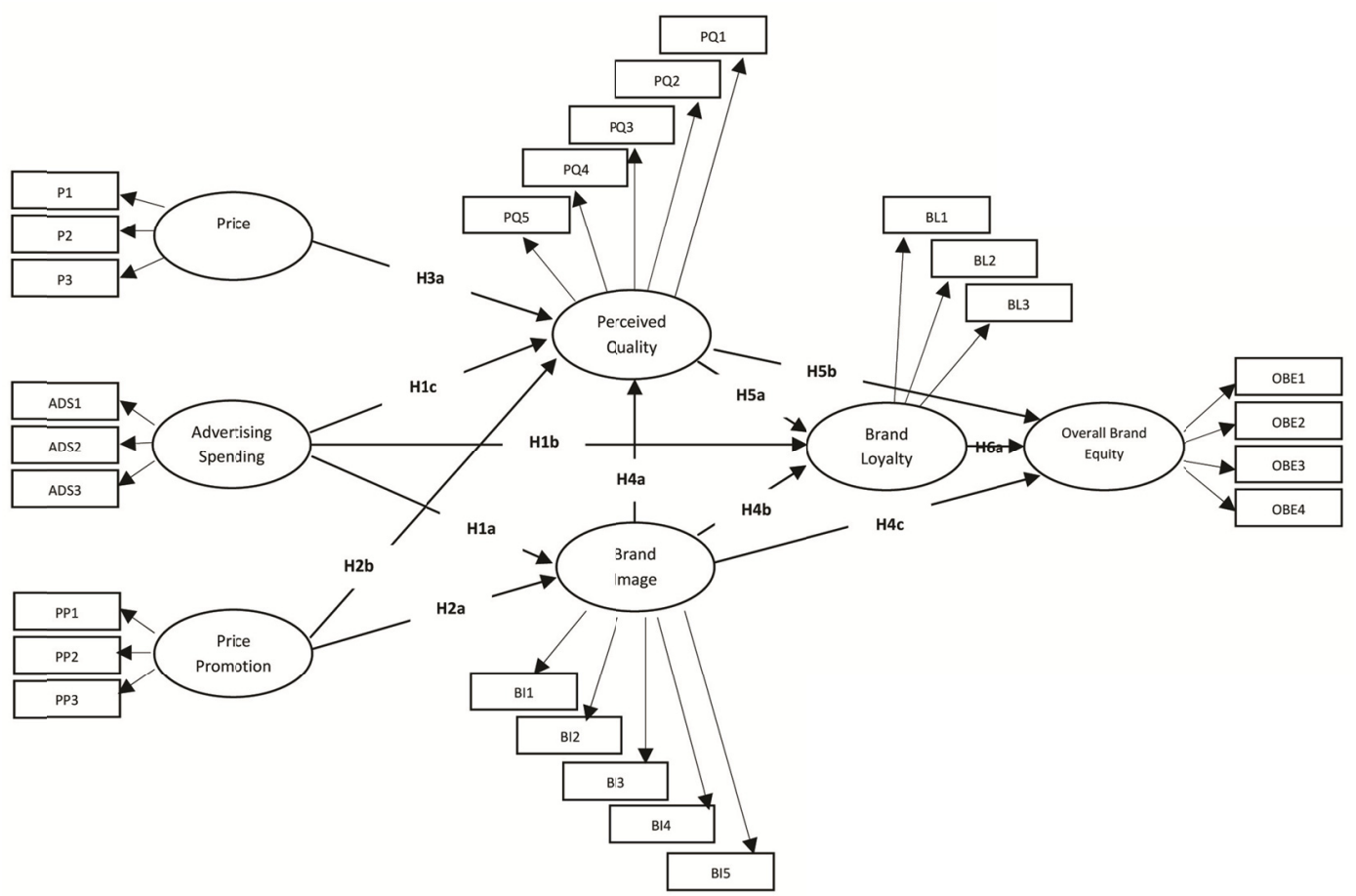

Figure 2. Structural model of the study

7 latent constructs and 26 observed variables were included for testing the proposed structural model. The model posits the selected perceived marketing activities (price, advertising spending and price promotion) as antecedents of brand equity dimensions (perceived quality, brand image and brand loyalty). Furthermore, these brand equity dimensions acting as endogenous mediating constructs were related to the last endogenous construct, overall brand equity (OBE). In total, 12 paths were examined.

Goodness-of-fit statistics indicating the overall acceptability of the structural model in both groups are presented in Table 9. All fit indexes met the recommended values indicating an acceptable model fitness level in both samples.

Table 9. Model fit statistics of the proposed model

\begin{tabular}{lll}
\hline Goodness-of-fit Statistics & Ghana & China \\
\hline Chi-square/df & $481.821 / 284$ & $399.514 / 284$ \\
CFI & .918 & .955 \\
GFI & .858 & .877 \\
AGFI & .824 & .848 \\
RMR & .051 & .036 \\
IFI & .920 & .956 \\
NFI & .824 & .862 \\
RMSEA & .059 & .044 \\
\hline
\end{tabular}

\subsubsection{Relationship between Marketing Activities and Brand Equity Dimensions}

With respect to the effect of the perception of advertising spend or expenditure on brand image, brand loyalty and perceived quality, $\mathrm{H} 1 \mathrm{a}, \mathrm{H} 1 \mathrm{~b}$ and $\mathrm{H} 1 \mathrm{c}$ respectively; the results support $\mathrm{H1a}$ and $\mathrm{H} 1 \mathrm{c}$ in both samples. Thus the higher the advertising spend, the higher the brand image and the higher the perceived quality. However, the relationship between advertising spends and brand loyalty (H1b) was weak and insignificant in both Ghana and China. Empirical results were also found for the negative effects of price promotion on brand image and perceived quality in both samples. The results are in line with hypotheses H2a and H2b. The findings also support H3a. Price plays an important role in brand equity dimension. As such, price has a positive and significant influence on perceived quality. This was evidence in both groups. 
Table 10. Structural model estimates for relationship between marketing activities and brand equity dimensions - Ghana and China

\begin{tabular}{|c|c|c|c|c|c|c|c|}
\hline & & & & Ghana & & China & \\
\hline & & & & $\begin{array}{l}\text { Standardized } \\
\text { Estimate }\end{array}$ & $\mathrm{T}$ Value & $\begin{array}{l}\text { Standardized } \\
\text { Estimate }\end{array}$ & T Value \\
\hline \multicolumn{8}{|c|}{ Relationship between Marketing Activities and Brand Equity Dimensions } \\
\hline H1a & Advertising Spending & $\Rightarrow$ & Brand Image & 0.431 & 5.32 & 0.286 & 3.76 \\
\hline $\mathrm{H} 1 \mathrm{~b}$ & Advertising Spending & $\Rightarrow$ & Brand Loyalty & 0.091 & 0.88 & 0.054 & 0.69 \\
\hline $\mathrm{H} 1 \mathrm{c}$ & Advertising Spending & $\Rightarrow$ & Perceived Quality & 0.321 & 3.57 & 0.164 & 3.04 \\
\hline $\mathrm{H} 2 \mathrm{a}$ & Price Promotion & $\Rightarrow$ & Brand Image & -0.24 & -5 & -0.234 & -4.98 \\
\hline $\mathrm{H} 2 \mathrm{~b}$ & Price Promotion & $\Rightarrow$ & Perceived Quality & -0.147 & -3.12 & -0.164 & -5.13 \\
\hline $\mathrm{H} 3 \mathrm{a}$ & Price & $\Rightarrow$ & Perceived Quality & 0.176 & 1.93 & 0.488 & 6.51 \\
\hline
\end{tabular}

\subsubsection{Relationships of the Dimensions of Brand Equity to Brand Equity}

Regarding hypotheses about the relationships of the dimensions of brand equity, empirical support was found for hypotheses $\mathrm{H} 4 \mathrm{c}, \mathrm{H} 5 \mathrm{~b}$ and $\mathrm{H} 6 \mathrm{a}$ in both samples.

Hypotheses $\mathrm{H} 4 \mathrm{a}, \mathrm{H} 4 \mathrm{~b}$ and $\mathrm{H} 4 \mathrm{c}$ examined the relationship of brand image to perceived quality, brand loyalty and brand equity respectively. It was evident that among Ghanaians respondents, brand image was likely to help build brand equity $\left(\beta_{8}=0.189, \mathrm{t}\right.$ value $\left.=2.054\right)$ and brand loyalty $\left(\beta_{9}=0.292, \mathrm{t}\right.$ value $\left.=3.010\right)$. However the relationship between brand image and perceived quality $(\mathrm{H} 4 \mathrm{a})$ was low and not significant $\left(\beta_{8}=0.056, \mathrm{t}\right.$ value $=$ $0.68)$.

For Chinese, results reveal support for $\mathrm{H} 4 \mathrm{c}$, thus brand image is positively and significantly related to brand equity. Contrary to expectations, influence of brand image on perceived quality and brand loyalty was negative and not significant. The findings fail to support hypothesis $\mathrm{H} 4 \mathrm{a}$ and $\mathrm{H} 4 \mathrm{~b}$.

H5a establishes a positive relationship between perceived quality and brand loyalty in both samples, however this relationship was not significant among Ghanaian respondents thus not verified $(\beta=0.176, t=1.64)$. H5b was supported in each sample. The relationship of perceived quality to brand equity was higher for Ghanaians $\left(\beta_{8}=0.315\right)$ than for Chinese $\left(\beta_{8}=0.309\right)$.

Finally, hypothesis H6a posited that brand loyalty enhance brand equity. In both groups empirical results were found to support hypothesis H6a.

Among all these supported relationships, brand image to brand equity was the weakest among Ghanaians $\left(\beta_{8}=\right.$ $0.189)$ and Chinese respondents $\left(\beta_{8}=0.254\right)$.

Table 11. Structural model estimates for relationship between brand equity dimensions - Ghana and China

\begin{tabular}{|c|c|c|c|c|c|c|c|}
\hline & & & & Ghana & & China & \\
\hline & & & & $\begin{array}{l}\text { Standardized } \\
\text { Estimate }\end{array}$ & $\mathrm{T}$ Value & $\begin{array}{l}\text { Standardized } \\
\text { Estimate }\end{array}$ & T Value \\
\hline \multicolumn{8}{|c|}{ Relationship among Brand Equity Dimensions } \\
\hline $\mathrm{H} 4 \mathrm{a}$ & Brand Image & $\Rightarrow$ & Perceived Quality & 0.056 & 0.68 & -0.057 & -1.02 \\
\hline $\mathrm{H} 4 \mathrm{~b}$ & Brand Image & $\Rightarrow$ & Brand Loyalty & 0.292 & 3.01 & -0.014 & -0.18 \\
\hline $\mathrm{H} 5 \mathrm{~b}$ & Perceived Quality & $\Rightarrow$ & Overall Brand Equity & 0.315 & 2.94 & 0.309 & 2.73 \\
\hline H6a & Brand Loyalty & $\Rightarrow$ & Overall Brand Equity & 0.278 & 2.83 & 0.338 & 4.02 \\
\hline
\end{tabular}

\subsection{Multi-Group Analysis: Testing for Structural Invariance across the Ghana and China Samples}

The next stage was to examine the equivalence of the structural model across the two samples or groups by performing an invariance test of the model (Figure 1). To perform this, that is, whether the item loadings to factors were statistically invariant among the two samples, the unconstrained structural model was compared with the constrained model. In the unconstrained model, the factor structure is specified to vary across the Ghana and China samples, whereas the factor structure is constrained to be the same across samples in the constrained model. 
An unconstrained structural, in which the 12 paths were set to be different across the Ghanaian and Chinese samples, was examined. As Table 12 shows, the model yielded $\chi^{2}$ fit index of 881.347, with 568 degrees of freedom. The model was also supported by other values of fit. Its goodness-of-fit index (GFI) was 0.868 and adjusted goodness-of-fit index (AGFI) was 0.837 . CFI and NFI were 0.937 and 0.844 respectively, although somewhat less than the recommended cutoff criterion of 0.95 recommended by $\mathrm{Hu} \&$ Bentler (1999), still represented a relatively good fit across the two cultures.

Table 12. Model fit statistics for unconstrained and constrained models

\begin{tabular}{lll}
\hline Goodness-of-fit Statistics & Unconstrained Model & Constrained Model \\
\hline Chi-square/df & $881.347 / 568$ & $900.266 / 580$ \\
CFI & .937 & .936 \\
GFI & .868 & .865 \\
AGFI & .837 & .837 \\
RMR & .44 & .49 \\
IFI & .938 & .937 \\
NFI & .824 & .840 \\
RMSEA & .037 & .037 \\
\hline
\end{tabular}

To test the invariance of the 12 paths simultaneously, the unconstrained structure model was compared with the constrained model in which all the 12 factor loadings of the paths were constrained to be invariant across cultures. This unconstrained model was utilized as the baseline model.

The constrained model was nested within the baseline model, that is, the set of parameters estimated in the more restrictive model (constrained model) was a subset of the parameters estimated in the less restrictive model (baseline model). As shown in Table 13, the chi-square difference was statistically significant at the $90 \%(\mathrm{p}<0.1)$ confidence chi-square threshold significant $\left(\Delta \chi^{2}{ }_{12}=18.919\right)$. This difference was small in magnitude. This finding led to a rejection of the hypothesis of an invariant pattern of causal paths at the $90 \%$ confidence level.

Table 13. Chi Square difference test results for unconstrained and constrained structural model

\begin{tabular}{llll}
\hline Model & Chi-Square & Degrees of Freedom & P-Value \\
\hline Unconstrained & 881.347 & 568 & 0.000 \\
Constrained & 900.266 & 580 & 0.000 \\
Difference & 18.919 & 12 & 0.091 \\
\hline
\end{tabular}

As a result, a series of invariance tests of the paths were conducted independently to locate the invariant paths. In performing each of these independent tests, only one specific path was constrained to be equivalent across cultures and the remaining paths were relaxed to vary. As was conducted with the fully constrained model, this partial invariance structural model with only one specific path constrained was compared with the unconstrained structural model to test the equivalence of the focal path. For example, when the casual path from advertising spend factor (Adver) to the perceived quality factor (PerQual) was held invariant, as indicated in the chi-square difference $\left(\Delta \chi^{2} 1=2.514, \mathrm{p}=0.113\right)$, it demonstrated that the path was consistent across cultures ( $\mathrm{p}$-value was not statistically significant). The results of the individual tests for path invariance presented in Table 14 revealed that 3 out of the 12 paths (i.e. price factor to the perceived quality factor; brand image to the brand loyalty factor; and perceived quality factor to the overall brand equity factor) were not invariant across Ghana and China samples. These 3 paths were found to be inconsistent across the two samples. 
Table 14. Simultaneous tests of invariance for the structural model

\begin{tabular}{|c|c|c|c|c|c|c|}
\hline \multicolumn{3}{|l|}{ Competing Models } & $\chi^{2}$ & d.f & $\Delta \chi^{2}$ & $\Delta$ d.f \\
\hline \multicolumn{3}{|c|}{ Unconstrained Model: Factor loadings variant } & 881.347 & 568 & - & - \\
\hline \multicolumn{3}{|c|}{ Constrained Model: Factor loadings invariant } & 900.266 & 580 & $18.919 *$ & 12 \\
\hline Advertising Spending & $\Rightarrow$ & Perceived Quality & 883.861 & 569 & 2.514 & 1 \\
\hline Advertising Spending & $\Rightarrow$ & Brand Loyalty & 881.440 & 569 & 0.093 & 1 \\
\hline Advertising Spending & $\Rightarrow$ & Brand Image & 882.897 & 569 & 1.55 & 1 \\
\hline Price & $\Rightarrow$ & Perceived Quality & 884.790 & 569 & $3.443^{*}$ & 1 \\
\hline Price Promotion & $\Rightarrow$ & Perceived Quality & 881.407 & 569 & 0.06 & 1 \\
\hline Price Promotion & $\Rightarrow$ & Brand Image & 881.376 & 569 & 0.029 & 1 \\
\hline Brand Loyalty & $\Rightarrow$ & Overall Brand Equity & 881.379 & 569 & 0.032 & 1 \\
\hline Brand Image & $\Rightarrow$ & Perceived Quality & 882.118 & 569 & 0.771 & 1 \\
\hline Brand Image & $\Rightarrow$ & Brand Loyalty & 887.677 & 569 & $6.33 * * *$ & 1 \\
\hline Perceived Quality & $\Rightarrow$ & Brand Loyalty & 885.585 & 569 & $4.238^{* *}$ & 1 \\
\hline Perceived Quality & $\Rightarrow$ & Overall Brand Equity & 881.758 & 569 & 0.411 & 1 \\
\hline Brand Image & $\Rightarrow$ & Overall Brand Equity & 881.382 & 569 & 0.035 & 1 \\
\hline \multicolumn{3}{|c|}{ Constrained Model with 9 paths invariant } & 889.721 & 577 & 8.374 & 9 \\
\hline
\end{tabular}

Note. ${ }^{*} \mathrm{p}<0.1,{ }^{* *} \mathrm{p}<0.05, * * * \mathrm{p}<0.01$.

The test revealed that the metric in-equivalence occurred because of these three paths. Full invariance structure was not achieved however a partial invariance model was established. This partial invariance structural model was constructed with the 9 invariant causal paths constrained to be equivalent across the Ghana and China samples and the 3 non-invariant paths relaxed to vary across these two countries. The chi-square difference was not significant $(\chi 2$ d.f $=9=8.374, p>0.1)$, indicating the wholesome cross-cultural equivalence of the nine causal paths.

Table 15 reports the standard estimates and t-value of the causal path parameters of the partial invariance structural model and Figure 3 displays the invariant and non-invariant causal paths to the overall brand equity factor across the Ghana and Chinese samples.

Out of the 3 non-invariant causal paths, only 1 was significant across both countries, specifically, the path from the price factor to perceived quality. The other two paths, that is, brand image to brand loyalty and brand image to overall brand equity were not significant across both countries. The former was significant in the Ghana sample and the latter was significant in the Chinese sample but not in the Ghana sample.

Regarding the 9 invariant causal paths, 6 were significant and the minimum t-value was 3.88 and maximum was 6.64. The following paths, advertising spend to brand loyalty dimension, price promotion to perceived quality dimension and brand image to the perceived quality dimension were all insignificant. With the exception of price promotion factor path to brand image that was negative, the remaining significant 5 paths were all positive and these results supports previous studies findings.

Table 15. Estimates and t-value

\begin{tabular}{|c|c|c|c|c|c|c|c|c|}
\hline \multirow[t]{2}{*}{ Parameter } & & & \multicolumn{2}{|c|}{$\begin{array}{l}\text { Across Culture } \\
\text { Equivalence }\end{array}$} & \multicolumn{2}{|c|}{ Ghana Sample } & \multicolumn{2}{|c|}{ China Sample } \\
\hline & & & Estimate & T-Value & Estimate & T-Value & Estimate & T-Value \\
\hline Advertising Spending & $\Rightarrow$ & Brand Image & 0.372 & 6.64 & & & & \\
\hline Advertising Spending & $\Rightarrow$ & Brand Loyalty & $-0.05 *$ & -0.60 & & & & \\
\hline Advertising Spending & $\Rightarrow$ & Perceived Quality & 0.195 & 3.98 & & & & \\
\hline Price & $\Rightarrow$ & Perceived Quality & & & 0.176 & 1.93 & 0.488 & 6.51 \\
\hline Price Promotion & $\Rightarrow$ & Perceived Quality & $-0.019 *$ & -0.76 & & & & \\
\hline Price Promotion & $\Rightarrow$ & Brand Image & -0.174 & -5.61 & & & & \\
\hline Brand Loyalty & $\Rightarrow$ & Overall Brand Equity & 0.272 & 5.91 & & & & \\
\hline Brand Image & $\Rightarrow$ & Perceived Quality & $0.076^{*}$ & 1.58 & & & & \\
\hline Brand Image & $\Rightarrow$ & Brand Loyalty & & & 0.292 & 3.01 & $-0.014^{*}$ & -0.179 \\
\hline Perceived Quality & $\Rightarrow$ & Brand Loyalty & & & $0.176^{*}$ & 1.91 & 0.396 & 5.66 \\
\hline Perceived Quality & $\Rightarrow$ & Overall Brand Equity & 0.33 & 3.88 & & & & \\
\hline Brand Image & $\Rightarrow$ & Overall Brand Equity & 0.24 & 4.21 & & & & \\
\hline
\end{tabular}




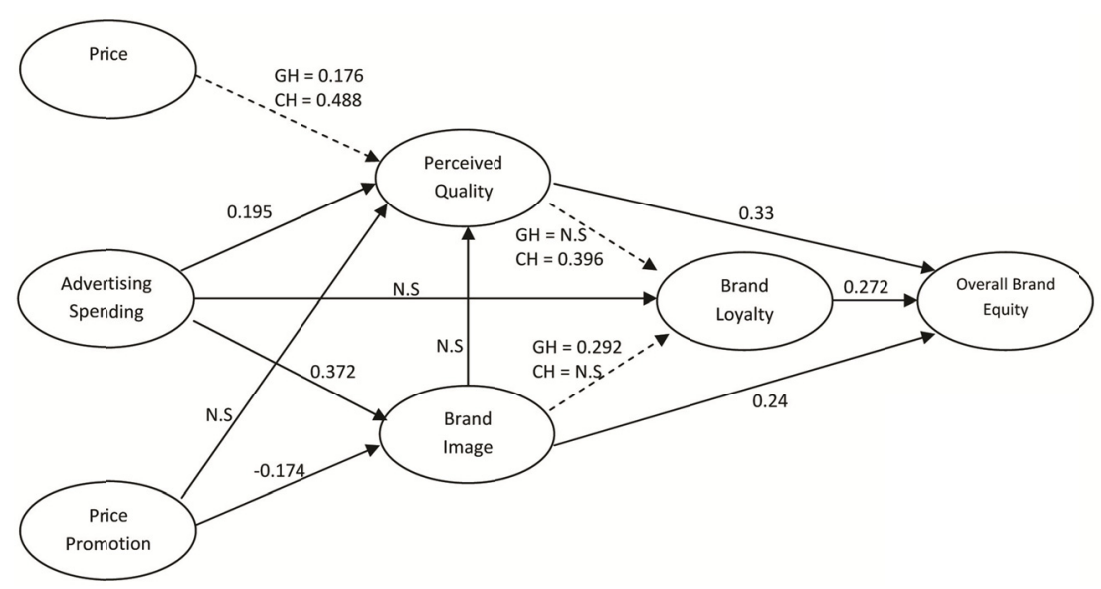

Figure 3. Invariant and Non-invariant causal paths to brand equity across the Ghana and Chinese sample Note. Solid lines represent invariant paths and broken lines represent non-invariant paths; Ghana (GH), China (CH), Not significant (N.S).

\section{Conclusion}

Several important implications were found about the brand equity formation process in the two markets. Findings from this study also suggest that cultural contexts significantly moderate marketing efforts and brand equity formation and thus provide several implications for international brand managers.

Consistent with previous studies, the findings of this study suggest that customers' perceptions and attitudes to a brand are determined by their past relationship or experiences with marketing activities of the respective brand over time. The knowledge consumers have about a brand and their response to their marketing activities determines the success of that particular brand. Marketing activities are link to the future success of a brand and thus it is important for brand managers to well-design their marketing activities in order to build, maintain and strengthen their brand.

\subsection{Summary of Findings}

The partial invariance structural model provides managers with valuable insights about similarities and differences between the Ghana and Chinese market's process of brand equity creation.

1) The effect of advertising spending on perceived quality and brand image were both positive and equivalent in both markets whiles effect on brand loyalty was negative and insignificant;

2) The effect of price on perceived quality was not equivalent in both markets, while the effect was positive in both markets but stronger in the Chinese market;

3) The effect of price promotion on brand image was negative and equivalent in both markets, while the effect of price promotion on perceived quality was also negative and equivalent in both markets, it was insignificant;

4) The impact of brand image to brand loyalty was not equivalent in both markets, while it was substantively positive in the Ghanaian market; this impact was negative in the Chinese market and insignificant;

5) The effect of brand image on perceived quality was positive and equivalent in both markets but insignificant;

6) The impact of perceived quality on brand loyalty was not equivalent in both markets, while it was positive in both the Chinese and Ghanaian market; it was insignificant in the later;

7) All brand equity dimensions (brand loyalty, perceived quality and brand image) impact on brand equity were positive and equivalent in both markets

\subsection{Discussion and Managerial Implications}

Consumers in both countries use price as a determinant of product quality. This is consistent with the findings of Yoo \& Donthu (2002) about the price-perceived quality relationship, which is well established through previous empirical research. In Ghana, many perceive products sold in malls and supermarkets which are highly priced to be of high quality.

In both markets, advertising is an effective tool to influence consumers purchase decision and build brand equity. Frequent advertising exposes the brand to consumers which leads to a more positive perception of brand quality (Yoo et al., 2000). Brand managers should invest more in advertisement to enhance their brand images and 
perceptions, thus ultimately strengthen the loyalty of consumers. Advertising is a great tool to develop, shape and manage brand image (estimate $=0.372 ; \mathrm{t}$ value $=6.64)$ than perceived quality (estimate $=0.195 ; \mathrm{t}$ value $=3.98$ ) Similar to Korea, both Ghana and China consumers are integrated into strong, cohesive in-groups showing less independent and more interdependent. As a consequence, consumers in both markets interdependently interpret the advertising message and make product purchase decision relying much on ingroup members' opinions. According to Yoo \& Donthu (2002), the impact of advertising becomes diluted due to collectivism and marketers should employ actual product performance in building brand equity in a collectivistic market (like Ghana, China and Korea).

Yoo \& Donthu (2002) found brand loyalty to be the most important brand equity dimension in both US and Korean samples, however this study shows perceived quality is a stronger determinant of brand equity than brand loyalty and brand image in the Ghana and Chinese samples. Despite the fact that perceived quality have a slightly non-significant impact on brand loyalty in the Ghanaian sample, the positive relationship found is consistent with previous studies. Perception of product quality is not a strong determinant of creating loyalty among Ghanaian consumers. Yoo \& Donthu (2002) cited strong uncertainty avoidance among the Korean sample compared to the US sample the reason for the high impact of perceived quality on brand equity. According to the Geert Hofstede website (https://geert-hofstede.com), Ghana is a society of high uncertainty avoidance with score of $65($ Korea $=85)$ and China is low with a score of 30 (lower than that US = 46). Findings of Yoo \& Donthu (2002) shows perceived quality had a greater impact on brand equity in the Korean sample (high uncertainty avoidance) than US (low uncertainty avoidance). Surprisingly, the effect of perceived quality on brand equity was equivalent in both Ghana and China that are positioned on different ends of uncertainty avoidance spectrum. A plausible reason for such finding in the China sample might be due to the constant search of high quality products by consumers. There is a general perception that product quality in China is poor and developed countries such as the US and Europe have raised entry barriers for its products. Product safety incidents such as melamine found in milk powder and infant formula; use of gutter oil, oil extracted from animal byproducts, oil collected from drains, etc as cooking oil have put many consumers on edge, always seeking for high quality products across product categories. So although uncertainty avoidance is low in China, which means they are suppose to accept uncertainty without much discomfort and takes risk easily, the concern of product quality outweighs the influence of uncertainty avoidance.

With regards to price promotion, it should be utilized with great caution in both markets. Consistent with previous studies including Yoo \& Donthu (2002) work, the current study also reveals price promotions has a negative impact on brand equity dimensions in both Ghana and Chinese samples. This harmful effect of price promotion on brand equity is a cross-cultural phenomenon. Use of price promotion in a long term has a detrimental effect on brand image in both markets.

All brand equity dimensions had a significant positive impact on brand equity. This finding shows that brand equity is rooted in these dimensions and brand management should be focus on all not just one. The usefulness of each dimension of brand equity is not uniform across diverse product categories and cultures. However, their importance to building brand equity cannot be overlooked therefore it is important for brand managers to know how each of these dimensions contributes to the overall brand equity.

Furthermore, the study's findings reveal the importance of managing loyalty as part of the brand management strategy. Brand loyalty is an important brand equity dimension in both markets. Loyal customers consistently will purchase or show preference for a certain product or brand over an extended period of time than non-loyal or switching customers. Brands currently in these markets or plans to enter should have a long term mentality and hence companies are well advised to design marketing strategies to build loyalty to enhance brand equity. Brand loyalty is considered by many authors as the heart of brand's value (Keller, 2003; Yoo et al., 2000).

Results also indicates the role of brand image as a vital determinant factor of consumer's brand choice among Ghanaian consumers but not enough to establish the superiority of a brand over other competing brands in China. This finding indicates that having a good brand image is not a guarantee of consumers perceiving your brand as high quality or repeat purchase of your brand. Brand managers should note that having a superior product is not enough; it must be remarkable and remembered.

\subsection{Limitations and Future Research}

Every research work has a certain degree of limitations and in this study, the limitations need to be articulated and considered.

First limitation of the study is the sample size. The number of countries included in the study was only two. Lower sample size has the potential to limit the ability to have statistically significant results. Another limitation 
is the product category used as stimuli used in collecting data for the study. Also, the current study used perceptual not actual measures of marketing efforts. Furthermore, marketing activities employed and examined are a few.

In view of this, future research should execute the study with a larger sample involving more countries across multiple brands. Future research should increase the number of marketing efforts by selecting brands that have similar marketing mix elements in various markets so as to include more activities and examine more detailed practices in order to more systematically examine the relationship between marketing efforts and brand equity building. Actual marketing variables should be use to investigate rigorously the causal effect of each marketing effort.

\section{References}

Aaker, D. (1991). Managing Brand Equity. New York: Free Press.

Aaker, D. A. (1991). Managing brand equity: capitalizing on the value of a brand name. Journal of Business Research, 29(3), 247-248. New York: The Free Press.

Aaker, D. A. (1996). Measuring brand equity across products and markets. California Management Review, 38(3), 102-120. https://doi.org/10.2307/41165845

Anderson, J. C., \& Gerbing, D. W. (1984). The effect of sampling error on convergence, improper solutions, and goodness-of-fit indices for maximum likelihood confirmatory factor analysis. Psychometrika, 49(2), 155-173. https://doi.org/10.1007/BF02294170

Atilgan, E., Aksoy, S., \& Akinci, S. (2005). Determinants of the brand equity: A verification approach in the beverage industry in Turkey. Marketing intelligence \& planning, 23(3), 237-248. https://doi.org/10.1108/02634500510597283

Blattberg, R. C., \& Neslin, S. A. (1990). Sales promotion: Concepts, methods, and strategies: Prentice Hall Englewood Cliffs, NJ.

Boulding, W., \& Kirmani, A. (1993). A consumer-side experimental examination of signaling theory: do consumers perceive warranties as signals of quality? Journal of Consumer Research, 111-123. https://doi.org/10.1086/209337

Bravo, G. R., Fraj, A. E., \& Martinez, S. E. (2007). Family as a source of consumer-based brand equity. Journal of Product \& Brand Management, 16(3), 188-199. https://doi.org/10.1108/10610420710751564

Buil, I., De Chernatony, L., \& Martínez, E. (2013). Examining the role of advertising and sales promotions in brand equity creation. Journal of Business Research, 66(1), 115-122. https://doi.org/10.1016/j.jbusres.2011.07.030

Campbell, D. T., \& Fiske, D. W. (1959). Convergent and discriminant validation by the multitrait-multimethod matrix. Psychological bulletin, 56(2), 81. https://doi.org/10.1037/h0046016

Chiong, W. et al. (2013). The salience network causally influences default mode network activity during moral reasoning. Brain, 136(6), 1929-1941. https://doi.org/10.1093/brain/awt066

Churchill Jr, G. A. (1979). A paradigm for developing better measures of marketing constructs. Journal of Marketing Research, 64-73. https://doi.org/10.2307/3150876

Cobb-Walgren, C. J., Ruble, C. A., \& Donthu, N. (1995). Brand equity, brand preference, and purchase intent. Journal of Advertising, 24(3), 25-40. https://doi.org/10.1080/00913367.1995.10673481

Cretu, A. E., \& Brodie, R. J. (2007). The influence of brand image and company reputation where manufacturers market to small firms: A customer value perspective. Industrial Marketing Management, 36(2), 230-240. https://doi.org/10.1016/j.indmarman.2005.08.013

Dabholkar, P. A., Thorpe, D. I., \& Rentz, J. O. (1995). A measure of service quality for retail stores: scale development and validation. Journal of the Academy of Marketing Science, 24(1), 3-16. https://doi.org/10.1177/009207039602400101

Dick, A. S., \& Basu, K. (1994). Customer loyalty: toward an integrated conceptual framework. Journal of the Academy of Marketing Science, 22(2), 99-113. https://doi.org/10.1177/0092070394222001

Doll, W. J., \& Torkzadeh, G. (1988). The measurement of end-user computing satisfaction. Mis Quarterly, 259-274. https://doi.org/10.2307/248851 
Farquhar, P. H. et al. (1992). Strategies for leveraging master brands: How to bypass the risks of direct extensions. Marketing Research, 4(3), 32.

Grover, R., \& Srinivasan, V. (1992). Evaluating the multiple effects of retail promotions on brand loyal and brand switching segments. Journal of Marketing Research, 76-89. https://doi.org/10.2307/3172494

Hair, J. F. et al. (2005). Multivariate data analysis. New Jersey: Prentice Hall: Upper Saddle River.

Hu, L. T., \& Bentler, P. M. (1999). Cutoff criteria for fit indexes in covariance structure analysis: Conventional criteria versus new alternatives. Structural Equation Modeling: A Multidisciplinary Journal, 6(1), 1-55. https://doi.org/10.1080/10705519909540118

Keller, K. L. (1993). Conceptualizing, measuring, and managing customer-based brand equity. The Journal of Marketing, 1-22. https://doi.org/10.2307/1252054

Keller, K. L. (2002). Strategic Brand Management: Building, Measuring and Management Brand Equity. London: Pearson Education Ltd.

Keller, K. L. (2003). Understanding brands, branding and brand equity. Interactive Marketing, 5(1), 7-20. https://doi.org/10.1057/palgrave.im.4340213

Kirmani, A., \& Rao, A. R. (2000). No pain, no gain: A critical review of the literature on signaling unobservable product quality. Journal of Marketing, 64(2), 66-79. https://doi.org/10.1509/jmkg.64.2.66.18000

Lassar, W., Mittal, B., \& Sharma, A. (1995). Measuring customer-based brand equity. Journal of consumer marketing, 12(4), 11-19. https://doi.org/10.1108/07363769510095270

Lavidge, R. J., \& Steiner, G. A. (2000). A model for predictive measurements of advertising effectiveness. Advertising \& Society Review, 1(1). https://doi.org/10.1353/asr.2000.0008

Leone, R. P., \& Srinivasan, S. S. (1996). Coupon face value: its impact on coupon redemptions, brand sales, and brand profitability. Journal of Retailing, 72(3), 273-289. https://doi.org/10.1016/S0022-4359(96)90030-5

Lindsay, M. (1990). Establish brand equity through advertising. Marketing News, 24(2), 16.

Low, G. S., \& Lamb Jr, C. W. (2000). The measurement and dimensionality of brand associations. Journal of Product \& Brand Management, 9(6), 350-370. https://doi.org/10.1108/10610420010356966

Netemeyer, R. G. et al. (2004). Developing and validating measures of facets of customer-based brand equity. Journal of Business Research, 57(2), 209-224. https://doi.org/10.1016/S0148-2963(01)00303-4

Nunnally, J. (1978). C.(1978). Psychometric theory. New York: McGraw-Hill.

Oliver, R. L. (1999). Whence consumer loyalty? The Journal of Marketing, 33-44. https://doi.org/10.2307/1252099

Pitta, D. A., \& Prevel Katsanis, L. (1995). Understanding brand equity for successful brand extension. Journal of Consumer Marketing, 12(4), 51-64. https://doi.org/10.1108/07363769510095306

Rice, B., \& Bennett, R. (1998). The relationship between brand usage and advertising tracking measurements: International findings. Journal of Advertising Research, 38, 58-66.

Roberts, J. et al. (2004). Measuring sources and outcomes of brand equity. Paper presented at the Communication in ANZMAC Conference, Australian and New Zealand Marketing Conference.

Simon, C. J., \& Sullivan, M. W. (1993). The measurement and determinants of brand equity: A financial approach. Marketing Science, 12(1), 28-52. https://doi.org/10.1287/mksc.12.1.28

Spector, P. E. (1992). Summated rating scale construction: An introduction. Thousand Oaks, California: Sage. https://doi.org/10.4135/9781412986038

Srivastava, R. K., \& Shocker, A. D. (1991). Brand equity: a perspective on its meaning and measurement. Marketing Science Institute.

Taylor, S. A., Celuch, K., \& Goodwin, S. (2004). The importance of brand equity to customer loyalty. Journal of Product \& Brand Management, 13(4), 217-227. https://doi.org/10.1108/10610420410546934

Tong, X., \& Hawley, J. M. (2009). Measuring customer-based brand equity: empirical evidence from the sportswear market in China. Journal of Product \& Brand Management, 18(4), 262-271. https://doi.org/10.1108/10610420910972783 
Villarejo-Ramos, A. F., \& Sánchez-Franco, M. J. (2005). The impact of marketing communication and price promotion on brand equity. The Journal of Brand Management, 12(6), 431-444. https://doi.org/10.1057/palgrave.bm.2540238

Washburn, J. H., \& Plank, R. E. (2002). Measuring brand equity: An evaluation of a consumer-based brand equity scale. Journal of Marketing Theory and Practice, 10(1), $46-62$. https://doi.org/10.1080/10696679.2002.11501909

Wu, P. C., Yeh, G. Y. Y., \& Hsiao, C. R. (2011). The effect of store image and service quality on brand image and purchase intention for private label brands. Australasian Marketing Journal (AMJ), 19(1), 30-39. https://doi.org/10.1016/j.ausmj.2010.11.001

Yoo, B., \& Donthu, N. (2001). Developing and validating a multidimensional consumer-based brand equity scale. Journal of Business Research, 52(1), 1-14. https://doi.org/10.1016/S0148-2963(99)00098-3

Yoo, B., \& Donthu, N. (2002). Testing cross-cultural invariance of the brand equity creation process. Journal of Product \& Brand Management, 11(6), 380-398. https://doi.org/10.1108/10610420210445505

Yoo, B., Donthu, N., \& Lee, S. (2000). An examination of selected marketing mix elements and brand equity. Journal of the Academy of Marketing Science, 28(2), 195-211. https://doi.org/10.1177/0092070300282002

Zeithaml, V. A. (1988). Consumer perceptions of price, quality, and value: a means-end model and synthesis of evidence. The Journal of Marketing, 2-22. https://doi.org/10.2307/1251446

\section{Copyrights}

Copyright for this article is retained by the author, with first publication rights granted to the journal.

This is an open-access article distributed under the terms and conditions of the Creative Commons Attribution license (http://creativecommons.org/licenses/by/4.0/). 